\title{
As (des)construções de gênero e sexualidade no recreio escolar
}

CDD. 20.ed. 301.418

796.05

\author{
Ileana WENETZ* \\ Marco Paulo STIGGER* \\ Dagmar Estermann MEYER*
}

\section{Resumo}

Neste estudo, a partir das vertentes dos Estudos Culturais e de Gênero que se aproximam do pósestruturalismo de Foucault, procuramos compreender como são atribuídos significados de gênero que constituem modos diferenciados de ser menino ou menina no espaço do recreio de uma escola pública de Porto Alegre, no Brasil. Através de um trabalho etnográfico que teve a duração de um ano e com realização de entrevistas com crianças, focalizamos uma segunda e uma terceira série do ensino fundamental e identificamos uma aprendizagem não-oficial e não-intencional que ocorre nas brincadeiras das crianças, onde elas aprendem formas de ser meninos e meninas. Neste contexto, percebemos que existe uma ocupação dos espaços do pátio da escola segundo o gênero, que inclui diferentes maneiras de ocupação e negociação configurando uma geografia do gênero. Também observamos uma construção da sexualidade na escola, na qual a homossexualidade é circunscrita em detrimento da norma da heterossexualidade.

Palavras-chaVe: Etnografia; Infância; Gênero; Sexualidade.

\section{Introdução}

(...) pátio, sol, sirene, gritos, corre-corre, risadas, quadras, lanche, bebedouro, chutes, salgadinhos, conversa, passeio, funcionário olhando as crianças, camisetas, corda, segredinhos, futebol, mochilas, jogo de mãos, empurra-empurra, uma menina arruma o cabelo, outras duas fofocam, bola para cima e para baixo, ventinho na cara, um menino amarra o cadarço, uma professora atravessa rapidamente o pátio, alunos e alunas sentados nos bancos, passa outra professora, meninos brincam com fichas no chão, filas, descanso, passam duas professoras, muitas vozes juntas que não permitem ouvir ninguém, dois meninos se empurram, crianças sentadas no canteiro, uma turma joga basquete na quadra (...) (Diário de Campo, 20/mar./2004).

Alguém reconhece esse momento? Ele fez/faz parte do quotidiano de muitos de nós, seja na época em que éramos escolares, seja como professores que aí atuamos. Esse é espaço de movimentos, de cores, sons, sinais, ruídos. Nele a vida da escola aparece latente, se transforma, constantemente, para além das salas, das tarefas, dos cadernos e dos objetivos escolares formais.
O recreio é um momento em que se misturam as vozes das crianças (com risadas ou gritos estridentes) e das professoras (com advertências, chamados à ordem). No recreio, todos esses barulhos misturamse num som contínuo. A sirene, sempre altíssima, repentinamente cala todos esses ruídos múltiplos e disformes. É assim que a escola marca seu próprio som, seu próprio ritmo, regulariza, delimita a entrada e a saída, a hora de fazer fila. Mas também acontece um silêncio no recreio: o das vozes que não se ouvem. Quem não fala ou fala e se confunde com as outras falas? Quem resiste a fazer alguma coisa não permitida? Quem se desvia? Quem cria?

Todas essas misturas de sons, de atividades e de silêncios acontecem em diferentes espaços da escola e se potencializam no recreio, esse espaço que se apresenta diante de nós como um caos. E é neste momento específico do quotidiano escolar que pudemos observar como brincam meninos e meninas, em pequenos grupos ou não, em pares com colegas de turma, na maior parte das vezes estando as meninas de um lado e os meninos do outro. Podemos dizer que, de maneira geral, as meninas pareciam mais "tranquilas" e "passivas", enquanto os meninos se 
mostravam mais "inquietos" e "agressivos". Percebemos ainda que os meninos gostavam de jogar futebol enquanto as meninas gostavam de pular corda.

Embora essas diferenças comportamentais possam parecer, no senso comum, por demais óbvias e naturais, elas fizeram com que nós nos questionássemos sobre por que elas se definiam dessa maneira. Será que era mesmo natural que fosse assim? Ou isso seria algo apreendido? E será que essas divisões e preferências aconteciam sempre do mesmo modo e de uma maneira homogênea? Como isto é construído?

A possibilidade de refletir sobre essas questôes relacionadas ao gênero corresponde a uma série de questionamentos sobre os quais nos debruçamos neste artigo. Representa a busca de respostas para inquietudes que se apresentam na prática do dia-adia escolar e se explicitam nas expressões das crianças. Já respondendo a algumas questōes feitas acima e partindo do pressuposto de que essas diferenças comportamentais - assim como outras - não são naturais, nos perguntamos: como se tornam possíveis essas diferenças entre feminilidade e masculinidade? Será que falamos de uma única feminilidade e masculinidade? Estas diferenças são re-produzidas e legitimadas tanto em momentos "oficiais" de aprendizagem quanto naqueles "não oficiais" ou de dispersão? Como esses processos de aprendizagem acontecem no recreio?

Orientados inicialmente por estas perguntas, procuramos, neste estudo, a partir das vertentes dos Estudos Culturais e de Gênero que se aproximam do pós-estruturalismo de Michel FOUCAULT ${ }^{\mathrm{a}, 1-2}$, entender como são produzidos re-produzidos os significados de gênero que atravessam ou instituem modos diferenciados de ser menino e de ser menina num contexto particular, o recreio escolar. Assim, tendo como objeto de estudo a brincadeiras que acontecem no recreio escolar, perguntamos: quais são os significados sociais atribuídos ao corpo e ao gênero nas práticas corporais que permeiam o recreio da primeira à quarta série de uma escola pública de Porto Alegre, no Brasil? Esta questão central foi dividida em algumas perguntas especificas: como e o que as crianças aprendem sobre feminilidades e masculinidades brincando no recreio? Que significados meninas e meninos conferem, concedem, consentem em relação a essas aprendizagens? Como o corpo torna-se alvo de determinados discursos que evidenciam algumas representaçōes em detrimento de outras? Como as práticas corporais vivenciadas no recreio disciplinam corpos de meninos e meninas, generificando-os?

\section{Dos diferentes modos de "olhar"}

Em busca de pistas a estas questões, realizamos um trabalho etnográfico, onde procurando problematizar as aprendizagens que acontecem nesse espaço, identificando, nele, os diferentes discursos que evidenciam algumas representações de gênero em detrimento de outras. Isto foi realizado entendendo que as brincadeiras, as falas, as disputas e as diversas ações que se realizam mesmo num espaço considerado tradicionalmente como espontâneo e livre, carregam significados que as crianças produzem, atribuem e disputam a partir do meio social no qual se encontram.

Foi, então, por um período de um ano, realizado um processo de investigação que incluiu os diferentes momentos da rotina da escola (entrada e saída das crianças, atividades em sala de aula, passeios, hora do lanche e festas escolares) e também atividades fora dessa rotina, como as festas de aniversário de algumas crianças e os passeios que ocorreram fora do universo escolar. Além da observação direta em todo o contexto da escola, fizemos uso da observação participante ${ }^{3-5}$ focalizada no recreio e nas brincadeiras que ali ocorriam. Neste universo, através da "bola de neve", realizamos conversas informais com diversas crianças, assim como com diferentes pessoas da comunidade escolar; além disto, realizamos entrevistas com 58 crianças $^{3,7-11}$.

O trabalho investigativo foi desenvolvido desta forma, por considerarmos que o estudo etnográfico possibilita uma analise por dentro na tentativa de tornar "o familiar em estranho"b; ou seja, observar no dia-a-dia, aquilo que percebemos como natural, com a intenção de "descobrir como se constroem e se desenvolvem práticas culturais que - à primeira vista e por estarem tão fortemente inseridas em nossas vidas - costumamos considerar quase que parte de nossa natureza" ${ }^{5}$ (p.4, grifo nosso) ${ }^{\mathrm{c}}$.

A opção por esse tipo de estudo está fundamentada na sua característica de se constituir num processo de observação que possibilita uma descrição detalhada de um contexto particular. Porém, com a intenção de investigar no lugar e não o lugar, observamos as relações de gênero que ocorriam na escola e no recreio; da mesma forma, as análises que foram efetuadas também não se focalizaram 
nos sujeitos e em suas falas, mas antes nos discursos e nas representaçóes que davam sentido às suas falas e nas relações que os constituíam como sujeitos masculinos e femininos ${ }^{\mathrm{d}}$.

\section{Recreio: um espaço de aprendizagens}

Mesmo que existam estudos desenvolvidos nos pátios das escolas ${ }^{12-13}$, comparado com outras temáticas pedagógicas, institucionais ou curriculares, as atividades que acontecem no recreio escolar parecem ter sido menosprezadas, como objeto de estudo. Talvez isto ocorra pelo fato de que as coisas que ocorrem no tempo livre (os jogos e as brincadeiras, em especial) sejam ainda consideradas como temas menores, já que são vistas como momentos não sérios da vida da escola, diferentes das atividades intelectuais que acontecem no contexto escolar. Este olhar à distância também faz com que o recreio seja entendido como um espaço no qual as brincadeiras não têm ordem, no qual as crianças apenas brincam, se machucam, brigam e gritam. Ele também é visto como um espaço de liberdade, pois os adultos não estão presentes.

Mas um olhar de perto nos reservaria surpresas: o processo investigativo nos mostrou que o recreio tem vários sentidos (estudantes, funcionários, professores e a direção da escola atribuem sentidos diferentes ao recreio) e também uma rotina própria não vinculada apenas ao espaço, ao tempo e às atividades que nele ocorrem. Esse universo, que, num primeiro olhar pode parecer ininteligível, tem, dentro de si, uma ordem possível de ser identificada através da observação de indivíduos, de grupos e/ou de atividades diferenciadas. São grupos e atividades que, mesmo não sendo fixos nem permanentes, possuem uma certa regularidade. Separados por gênero, por idade, por interesse, por parentesco, por vizinhança, por amizade e outros tipos de relaçôes sociais, os indivíduos articulam significados no convívio cotidiano da escola.

É desta forma que o recreio se constitui também um espaço de aprendizagem social, no qual as normas e as regras acerca de diferentes aspectos da cultura dos estudantes são apreendidas através de uma interação nem oficial nem curricular da escola. Não são relaçôes intencionais, mas aprendizagens veiculadas socialmente e informalmente, nas quais os significados e os comportamentos esperados são ensinados e aprendidos sem que isso seja o objetivo da escola. No convívio coletivo elas vão se configurando, se conformando e criando uma rede de articulações muito complexas, que faz parte da cultura dos estudantes.

Mas, se o recreio está inserido na cultura dos estudantes, ele também vai configurando sua própria cultura, entendida como a cultura do recreio, que "requer aprender um conjunto de regras e rituais [...] que podem ser diferentes para meninos e meninas"14(p.24). Entre outros aspectos, esta cultura do recreio se materializa em diferentes espaços constituindo um "mapa do recreio".

\section{O mapa do recreio}

$\mathrm{O}$ que estamos denominando mapa do recreio é a distribuição dos diferentes grupos e subgrupos no espaço físico onde o recreio acontece. Como referimos anteriormente, eles não são fixos nem permanentes, mas possuem uma regularidade, vinculada a diversos aspectos, como proximidade de interesses, idade, afeição e gênero. Muitos deles são constituídos por crianças das mesmas turmas, outros por vizinhança ou, mesmo, por relações de parentesco (observamos primos e irmãos convivendo, juntos, no recreio). Mas a observação permitiu perceber que a distribuição das crianças no espaço do recreio também se vincula ao espaço físico que a escola oferece. Conforme mostra a FIGURA 1, as características do espaço disponível se articulam com os outros aspectos acima mencionados. 
1) grupos de a dole scentes (meninos);

2 e 3)Quadra geralmente ocupada por adolescentes (meninas ou misto);

4,5 e 6)Grupos adolescentes mistos;

7) Quarta série, meninas;

8) Primeira série, meninas;

9) Grupo de meninos, segunda série;

10)Espaços de transição;

11) Grupo de terceira e quarta série, meninas;

12) Grupo de terceira série, meninas;

13) Vários grupos nãofixos entre primeira e segunda série (misto).

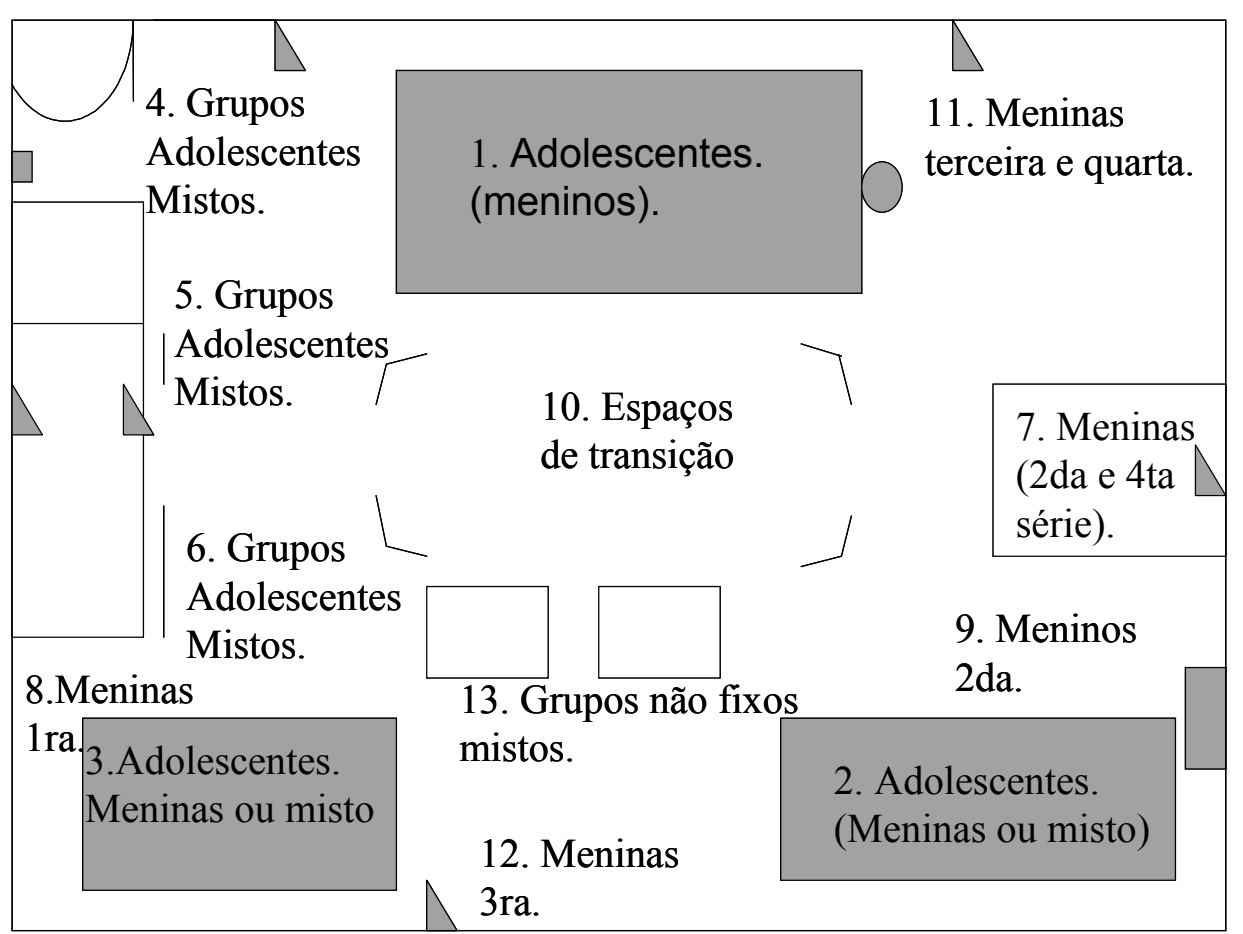

FIGURA 1 - Mapa dos grupos do recreio.

No universo estudado, na maior parte do tempo observado, os grupos da quinta à oitava série ocupavam as quadras esportivas, principalmente a quadra 1 , bem como o canto perto das escadas e os bancos na frente do refeitório, que correspondem aos números 4,5 e $6 . \mathrm{Na}$ maioria das situaçôes, eram os meninos que ocupavam as quadras, enquanto as meninas ficavam próximas aos bancos. Com esses espaços tomados pelos maiores, as crianças menores ficavam nas quadras 2 e 3 . A quadra 1 era sempre utilizada pelos meninos, que lá jogavam futebol ou basquete. As quadras 2 e 3 (voleibol), eram ocupadas pelos meninos quando a quadra de basquete já estivesse sendo usada por outros, da mesma idade, ou quando a maioria dos participantes fossem meninas. Acontecia desse modo porque as meninas preferem jogar voleibol e nem todos os meninos apreciam esse jogo; era muito mais provável observar grupos mistos jogando voleibol do que futebol.

O espaço detrás da quadra 2 era sempre ocupado por meninas das primeiras séries, enquanto os meninos jogavam futebol dentro da quadra. Isso também se aplicava à quadra 3 (voleibol), só que esse espaço também era usado pelos meninos da segunda série para jogar futebol. Em ambos os casos, isso só acontecia se os adolescentes não estivessem no pátio, porque, quando estavam lá, ocupavam o lugar através de diferentes imposiçôes e/ou negociaçôes.

Os meninos adolescentes ocupavam mais espaços, na maioria das vezes. Eles não só utilizavam as quadras esportivas, como também costumavam chutar a bola o mais alto e longe possível, cabendo a outros colegas pegá-la e chutá-la novamente. Desse modo, muitas vezes eles não ficavam num espaço específico, pois, conforme iam chutando a bola para várias direções, novos espaços e lugares iam sendo por eles invadidos. Também através desses mecanismos que os espaços iam sendo utilizados conforme a idade e por imposição corporal.

Os espaços entre as quadras de vôlei e os canteiros eram tomados por crianças da primeira à terceira série, que ficavam fazendo diferentes atividades, brincando de diferentes jogos ou comendo a merenda. $\mathrm{O}$ espaço sob a cobertura que antecede a entrada para as salas de aula (7) era o espaço das meninas da quarta série; comparado com os demais, era um espaço pouco disputado pelas crianças.

Em que pese este relato expressar o "mapa do recreio", é importante referir que, neste contexto, as crianças iam mudando de lugar segundo sua vontade e interesses; elas também se re-apropriavam dos espaços, fugindo um pouco daquilo que se esperava que neles fosse feito: mesmo que um banco fosse feito para sentar, no recreio, ele era também usado para pular, jogar, deitar, etc. Da mesma forma acontecia com as quadras esportivas, onde nem sempre se praticava a modalidade para a qual elas foram construídas. Vários eram os "movimentos" que aconteciam e que estão exemplificados abaixo, num excerto do diário de campo. 
Meninos de segunda série estão jogando futebol na quadra 2; três meninos que, de maneira geral, não participam do jogo de futebol se deslocam pelos espaços intermediários, brincando de lutas. Outros dois meninos da mesma turma ficam sentados perto da porta lateral, que dá acesso ao pátio - eles brincam de bater figurinhas. Enquanto isso, as meninas ficam passeando ou brincando de pega-pega. Já quase no final do recreio, alguns meninos saem correndo por todos os espaços. Pedro, que estava jogando futebol, sobe no teto pelas grades da janela para buscar a bola; duas funcionárias o advertem. A bola é encontrada e eles voltam a jogar. Minutos depois, Filipe deixa a torneira aberta, e também é advertido pelas funcionárias. Um grupo de meninas (terceira série) que estavam sentadas em um dos bancos perto do canteiro, passa a brincar de corrida; outras três meninas brincam num dos bancos e depois sentam no muro do canteiro. Num outro banco, está um grupo da primeira série, e, no banco da frente, está a segunda série, cada grupo brincando de coisas diferentes.

A partir da observação do recreio conseguimos perceber que, dentro daquilo que - a primeira vista - parece uma desordem, é possível encontrar uma ordem. Aquilo que parece uma complexidade ininteligível acaba por se transformar - aos olhos do pesquisador - numa complexidade inteligível ${ }^{15}$. Porém, como procuramos descrever, o fato de ter uma certa regularidade não implica que os espaços ocupados fossem fixos ou estáveis. De uma forma dinâmica, os espaços do recreio se organizavam a partir de vários aspectos já referidos, mas, dentre os quais, a idade e o gênero se destacavam. Esta "geografia generificada"16 se construía através de uma série de diálogos, imposições e negociações, por parte das crianças e dos/as adolescentes. De forma semelhante ao que encontrou Helena Altmann ${ }^{17}$, nesse contexto, ficou evidente que o esporte (futebol) era um meio de domínio masculino do espaço do recreio e que as meninas resistiam a essa dominação de diferentes formas, dentre elas, não jogando futebol e brincando de jogos não esportivos.

Tais elementos ou estruturas vão marcando e delimitando os espaços "adequados ou corretos", permeando as práticas sociais, classificando, distinguindo o lugar para cada coisa (ou para cada sujeito). Constituindo-se o que FouCAULT ${ }^{2}$ denominou de quadriculamento, determinava-se, desse modo, onde se deve estar, de que modo, por onde circular, por onde não circular, por onde e como fazer os deslocamentos. Tudo isso deixa implícito que, assim como o/a aluno/a não pode ocupar o espaço determinado para a diretora ou funcionária, ele também não pode ocupar o espaço destinado a outros colegas. Assim, a decisão de permanecer ou não num lugar não é uma decisão individual, já que - mesmo no momento dito livre do recreio - o fato de querer ocupar um espaço não significa que ele possa ser efetivamente ocupado.

Foi também possível perceber formas generificadas de serem estabelecidas negociaçôes/imposições entre os estudantes. Um exemplo disto ocorreu quando eram observados dois grupos de crianças: um formado por meninas da primeira série que brincava numa das quadras de vôlei e outro por meninos da segunda série, que jogavam na outra quadra. Num determinado momento, um grupo de adolescentes, em horário vago, chegou ao pátio e ocorreu o que está no relato a seguir.

Quando chegaram as garotas maiores com uma bola de vôlei, perceberam que as meninas menores estavam na quadra. Uma das adolescentes aproximou-se e perguntou: "vocês poderiam brincar atrás da quadra? Assim, a gente joga bola”. As meninas menores concordaram e, imediatamente, foram para trás da quadra e continuaram brincando, liberando pacificamente o espaço para as adolescentes. As meninas pequenas fizeram isso sem reclamar e não pareceram ficar inconformadas, pois ainda tinham um espaço para continuar a brincar. Não houve uma situação visível de imposição: elas tinham a opção de ficar no espaço, mas havia menos meninas pequenas do que adolescentes, justificando-se, assim, a troca de lugar.

No caso dos meninos, foi diferente. O grupo de adolescentes ocupou a quadra "sem pedir licença" e foi ocupando o espaço. Sem que os adolescentes se dirigissem aos meninos menores, a maior parte destes últimos saiu da quadra sem questionar. Mas um deles não se conformou com a "invasão" e começou aí uma ameaça corporal para que o menino menor se mantivesse fora da quadra. O "pequeno" ficou pisando na linha que delimita a quadra, olhando desafiadoramente para os adolescentes. Um deles aproximou-se, o ameaçando. Nesse suposto "diálogo", não foi dita nenhuma palavra. Quando o menino menor viu que seria superado corporalmente, desistiu de ficar na quadra e voltou a jogar futebol num espaço lateral, junto com seus colegas. Posteriormente, foi confirmada esta forma (masculina) de dominação do espaço. Em entrevista, um dos menores afirmou que, ao chegarem à quadra, os adolescentes apenas dizem: "ô meu, vão saindo” (Diário de Campo, 03/nov./04). 
Nesses exemplos podemos observar diferentes maneiras de se movimentar no espaço do recreio, segundo o gênero: as meninas se mostraram mais negociadoras e/ou se submeteram mais facilmente, enquanto os meninos mostraram-se mais violentos e agressivos. Isso converge com aquilo que comumente é falado no senso comum ("meninas são mais submissas, e meninos são mais violentos"), em que essas características fossem intrínsecas ou essencialmente vinculadas/decorrentes do sexo. Mesmo que, na maior parte dos casos isto tenha sido observado, nem sempre os meninos foram agressivos, e, tampouco as meninas se mostraram submissas. Em alguns casos, as meninas se mostraram capazes de "brigar", como durante a brincadeira do pega-pega, situação em que elas "se defendem" dos meninos, com chutes e pontapés.

Em outras situações, a negociação e o diálogo entre os grupos são totalmente dispensados, como aconteceu no exemplo que relatamos acima. As meninas da primeira série ficavam sempre brincando atrás da quadra de vôlei, que constitui um canto no pátio. Ao perguntar por que ficavam brincando sempre no mesmo lugar, tendo todo o pátio à sua disposição, elas responderam, sem hesitar: "porque aqui ninguém nos atrapalha!” (21/out/04).

Comportamentos generificados no espaço escolar já foram observados e descritos em outros trabalhos. No caso do estudo de Carlos NETO ${ }^{18}$, as crianças de oito a 12 anos preferiam, por ordem de importância, os espaços esportivos, depois as zonas de jogo livre, as zonas verdes e os espaços de aventura e, finalmente, as áreas de descanso. No caso da escola por nós pesquisada, o pátio se constituía por quadras esportivas, com algumas zonas de descanso demarcadas pelos bancos. Com tão poucas opçōes, os primeiros espaços a serem ocupados eram as quadras esportivas, dominadas por adolescentes masculinos, estes que - como já dissemos - se impunham pelo tamanho corporal e pela idade. Identificamos essa divisão dos espaços como classificações dos/as próprios/as alunos/as, pois, na escola pesquisada, essa divisão não estava estabelecida "oficialmente". Mesmo assim, os/as alunos/as sabiam para onde se dirigir quando chegavam ao pátio da escola, no horário do recreio.

Em um estudo etnográfico sobre brincadeiras do recreio em escolas do norte de Londres, EpsTEIN et al. ${ }^{19}$ também observaram como existia uma geografia do gênero nos pátios. Embora os autores tivessem considerado que as crianças concebem ou constituem as suas identidades de forma mais aberta e flexível do que os adultos, eles identificaram que os espaços mais ocupados pelos meninos eram as quadras esportivas, o que lhes permitia uma reprodução das identidades culturais entendidas como hegemônicas. Sobre isso, BOYLLE et al..$^{20}$ consideram que, nas negociações entre as fronteiras existentes no momento do recreio (das brincadeiras, do gênero e o modo de realizá-las), as crianças reforçam suas identidades de gênero.

Também, Barrie ThORNE ${ }^{16}$ estudou o pátio de escolas norte-americanas e observou que meninos ocupavam dez vezes mais espaços do que meninas, principalmente no que se refere aos espaços esportivos. Em relação a esse aspecto, GRUGEON ${ }^{14}$ entende que, com um simples olhar no pátio do recreio, é possível observar agrupamentos de meninas que denotam certa intimidade e meninos correndo de um lado para o outro. Isso também pôde ser observado na escola brasileira que estudamos, onde eram os meninos que mais ocupavam as quadras esportivas. Mas também foi possível observar outros movimentos e estratégias de ocupação: mesmo quando os meninos não ocupavam as quadras, utilizavam mais espaços, seja correndo, seja dando grandes chutes na bola de um canto ao outro do pátio, invadindo os outros ambientes. Enquanto isso, as meninas ficavam em grupos menores e de maneira mais passiva, sentadas ou em pé, quase sempre conversando, mas também dançando, como veremos a seguir.

\section{A generificação das práticas corporais no recreio: a dança como exemplo}

Diferentes estudiosas da área consideram que o gênero se amplia para além da noção de papéis sociais $^{\text {, }}$, abrangendo todas as formas de uma construção social, cultural e linguística dentro das quais se diferenciam homens e mulheres, incluindo ai seus corpos ${ }^{21-24}$. Essa perspectiva permite ampliar as análises e possibilita refletir, indagar e problematizar sobre o modo como determinadas posições atribuídas a mulheres e homens são produzidas como se fossem desígnios naturais.

Essas exigências sociais que se estabelecem através de mecanismos de poder colocam-se também para meninos e meninas dentro do espaço do recreio, o que se confirmou no estudo desenvolvido, onde, 
além de configurar a sua organização, o gênero atravessa as próprias brincadeiras das crianças. No pátio, aconteciam simultaneamente diferentes brincadeiras e práticas esportivas, como voleibol, basquete, futebol, pular corda, elástico, pega-pega, jogos de mãos e danças. $\mathrm{Na}$ maioria das vezes, o basquete e o futebol eram praticados pelos adolescentes de gênero masculino, enquanto o voleibol era jogado pelas meninas adolescentes ou em grupos mistos. Os jogos de mãos e as danças eram as atividades preferidas das meninas da primeira à quarta série, enquanto os seus colegas meninos - da mesma idade - brincavam de lutas ou jogavam futebol.

Foi também possível identificar como as preferências por brincadeiras eram conformadas socialmente. De acordo com nossas observações, se alguma menina quisesse jogar futebol, ou não encontraria meninas suficientes para acompanhá-la nesta atividade, ou, mesmo que mostrasse ter capital esportivo $^{25}$ (p.31) ${ }^{\mathrm{h}}$ para tal, teria dificuldades para ser aceita nos jogos dos meninos.

Assim, observarmos que o recreio escolar está vinculado a diversas formas de controle/regulação sobre o corpo infantil ${ }^{1}$, onde diversos mecanismos contribuem para uma construção/conformação de meninas e de meninos, agindo no sentido de produzir uma imagem feminina ou masculina. Aqui vemos as pedagogias culturais ${ }^{26} \mathrm{e}$ outras instâncias sociais, que, de diferentes modos, atuam na construção de meninos e meninas como possuidores de diferentes características.

$\mathrm{Na}$ cultura específica do recreio, entre outras atividades, observou-se a prática da dança, com ou sem o acompanhamento de música. Isso nos levou a abordar mais algumas das diferenças generificadas no espaço do recreio, entendendo, como LOURO ${ }^{27}$ (p.61), que "gestos, movimentos, sentidos são produzidos no espaço escolar e incorporados por meninos e meninas, tornam-se partes de seus corpos. Ali se aprende a olhar e a se olhar, se aprende a ouvir, a falar e a calar; se aprende a preferir".

No início do trabalho de campo, observamos que a direção da escola mantinha música tocando durante os intervalos. Os/as alunos/as levavam CDs da sua preferência, e estes eram tocados durante o recreio. Observamos, também, que tanto meninos como meninas dançavam, acompanhando a música. Porém, meninos e meninas agiam de forma diferente no que se refere à atividade da dança, conforme mostra o excerto abaixo (Diário de Campo, 26/ago/02). $\mathrm{E}$ o que fazem os meninos enquanto as meninas dançam? Este foi um dos focos da observação.

\begin{abstract}
Meninas de diferentes idades estão dançando em fileiras. Algumas meninas não conhecem a dança e ficam imitando os movimentos - todas procuram conhecer. Essa atividade é importante para elas e é valorizada como tal, pois, quando chega uma delas com o CD, várias ficam por perto e forma-se um aglomerado de meninas com o mesmo interesse. Ficam todas de um lado para outro só conversando sobre as músicas. Além disso, a menina que leva o CD fica com a função de procurar a direção da escola, para que coloquem a música a tocar, para que todas possam dançar. A menina que conhece a coreografia fica ensinando as letras das músicas e os movimentos para as demais.
\end{abstract}

Enquanto isso, alguns meninos começam a se mostrar interessados pela atividade. Eles dançam, até que aparece um colega (menino) e os provoca, debochando do fato deles estarem dançando. Imediatamente, os meninos que estavam interessados pareciam já não ter interesse pela dança...

No começo das observaçôes, parecia que eram apenas as meninas que dançavam, já que elas estavam muito mais expostas nesta atividade; à primeira vista, parecia que os meninos não participavam das danças. Contudo, observando mais de perto, percebemos que tanto as meninas quanto os meninos estavam sob uma forte regulação da sua conduta, no que se refere à prática da dança: as meninas faziam o que se esperava delas (dançar) e os meninos faziam (ou tentavam fazer) o que se esperava deles (não dançar). Eles constituíam um grupo não tão exposto, mas nem por isso não-regulado. Eles constituíam um silêncio e precisavam se ajustar a um modelo de masculinidade que é preciso reforçar o tempo todo; e qualquer escorregada pode ser motivo suficiente para o deboche.

Enquanto as meninas dançavam, muitos meninos da mesma idade ficavam no entorno, como se estivessem apenas observando, mas dançando, também, ao seu modo. Eles dissimulavam os movimentos da dança e/ou os exageravam; fingiam que não dançavam, ora minimizando os gestos da dança, ora ridicularizando a sua execução. Em alguns momentos, mesmo que estivessem praticando outra atividade, a interrompiam e movimentavam-se no mesmo ritmo das meninas; outras vezes, mesmo que tivessem ficado sentados e apenas observando, ao levantar, mostravam que conheciam todos os passos da coreografia que estava sendo feita pelas meninas. Ou seja, estavam interessados e bastante atentos. Porém, eles faziam qualquer coisa para que não se pudesse afirmar que estavam realizando o movimento tal 
como as meninas Além disto, mesmo que vários deles dançassem no recreio, quando entrevistados, muitos dos meninos não assumiram que participavam das danças das meninas: "o recreio era legal com música [pois] era legal ver as meninas dançarem" .

As descrições acima nos ajudaram a entender como vários significados sociais se fazem presentes no quotidiano escolar, onde diversos mecanismos culturais contribuem para a conformação de meninas e meninos. Ao observá-los imbricados na música e na dança, procuramos problematizar a construção da feminilidade e da masculinidade. Enquanto as meninas dançam e, explicitamente, mostram seus corpos, os meninos parecem fazê-lo em silêncio ou de formas caricaturadas: eles não dançam ou dançam ridicularizando os movimentos porque eles precisam reforçar sua masculinidade. Aqui, podemos retomar nossos pressupostos de que a linguagem constitui parte de todo o processo de significação. Também podemos perceber a música e a dança como elementos educacionais que acabam veiculando determinados significados e não outros.

\section{A construção do(s) gênero(s) e da(s) sexualidade(s) no recreio}

Como vimos, no espaço do recreio as crianças não brincam todas juntas, não fazem sempre o que querem nem brincam em todos os espaços; não fazem sempre o que elas gostariam mas também não brincam sempre daquilo que esperamos nem da forma que nós imaginaríamos que fizessem. $\mathrm{O}$ gênero e a sexualidade no recreio podem ser observados através da constituição dos próprios grupos e suas brincadeiras. Para refletir sobre esse assunto escolhemos situações referentes a duas turmas que apresentavam características particulares: uma segunda série e uma terceira série.

Na terceira série, observamos uma vinculação especifica das brincadeiras com o gênero que também acontecia com os meninos. João gostava de gostava de brincar de brincadeiras consideradas como tipicamente femininas, elástico, pular corda, pega-pega e vôlei. Nunca brincava de futebol, sempre ficava com as meninas e não realizava nenhuma atividade com os meninos, nem na sala de aula nem fora dela. Usava roupas tipo surfista, fazia luzes nos cabelos e os arrumava com gel. Por estas razões ele recebia o apelido de "bicha" por parte dos colegas meninos e de crianças de outras séries também. Isso era tão corriqueiro que observamos várias situaçōes em que ele era chamado assim, inclusive por um estagiário da escola: "olha o jeito que ele caminha", disse ele, ao tentar justificar o apelido que era dado a João. Neste contexto, a prática do futebol parecia ser colocada quase como uma obrigação para um menino; não fazer o que se esperava de um menino, levava-o a ser classificado como desviante. Análise semelhante foi desenvolvida em uma escola primaria de Londres, onde SWAIN ${ }^{28}$ também observou como o corpo é "docilizado" e como este mecanismo atuava através do futebol.
As próprias falas das crianças permitem observar a instauração de uma norma de linguagem que pode atuar de maneira repetida sobre a sexualidade e gênero das crianças, operando como uma produção de identidades. Por exemplo, Janaína enuncia que "as meninas de outras turmas que chamam ele [João] de bicha, [é] só porque ele anda com menina”. Mas Janaína diz que ele pode brincar do que ele quizer, desde que não queira namorar homem: "o João não tem que se importar se ele quiser andar com menina. Ou ele quer namorar homem? Não, né?!". Nessas falas, podemos observar como João era visto pelas meninas:elas o aceitavam e concordavam que ele brincasse com elas, mas entendendo que ele deveria manter sua heterossexualidade.

Em relação a estes aspectos, outros exemplos se relacionavam, vinculados a colegas da mesma turma de João. No primeiro caso, temos Pedro, que dançava balé fora do período da escola, mas no horário escolar só brincava de futebol e pertencia a um grupo de colegas, composto só por meninos. Como ele era um menino que fazia as coisas que um menino deveria fazer quase ninguém o importunava, apesar dos outros meninos saberem que ele praticava balé. Além disto, se alguém o provocasse verbalmente (eventualmente ele era importunado por dançar balé), ele respondia com agressōes, correspondendo ao comportamento aguerrido usualmente esperado/ caracterizado como masculino.

E o que acontece com outras crianças que atravessam as fronteiras de gênero, como as meninas que brincam de futebol? Nesse caso, perguntamos a Aline se alguém a importunava por ela preferir jogar futebol com os meninos, e ela respondeu que não. A maioria das crianças reconheceu que não a provocavam, mas, segundo Brenda, "às vezes os meninos pegam no pé 
dela, [dizendo] que ela é meio menino [...] que ela tem jeito de menino, até a voz dela, falam que é de menino; ela quer jogar bola e nunca vai brincar com as meninas de pular corda". Apesar deste relato, apelidar as meninas referindo-se à sua sexualidade nunca foi presenciado pelos pesquisadores em campo, o que leva a considerar que - se acontecia - era de uma forma bem mais sutil e difusa do que no caso dos meninos. Isto parece ter sido estabelecido para não desequilibrar a hegemonia da heterossexualidade e a dicotomia tradicional homem-mulher.

Esses exemplos desarranjam tanto a fixidez da feminilidade e da masculinidade apresentadas com artigo definido singular ( $a$ menina e $o$ menino) quanto a narrativa hegemônica da dominação masculina e da subordinação feminina "per se". Este desarranjo também vem sendo visibilizado em outras situações, qual seja, a de que as redes de vigilância e controle do gênero e da sexualidade parecem estreitar-se mais, contemporaneamente, em torno dos corpos masculinos quando se trata de cruzamentos ou borramentos de fronteiras historicamente instituídas para a masculinidade heterossexual.

Mesmo entre crianças muito pequenas (4-6 anos) podem ser encontradas ressonâncias do discurso homofóbico presente na sociedade mais ampla, quando as crianças rejeitam e rotulam comportamentos que fogem aos padróes estabelecidos pela cultura em relação à masculinidade hegemônica. Não raramente, os meninos utilizam, de forma mais freqüente do que as meninas, termos como "bichinhas", "gays" e "boiolas" para referir-se aos meninos transgressores das brincadeiras e comportamentos considerados como sendo masculinos nessa idade e contexto; o mesmo ocorre em relação às meninas que transgridem essas fronteiras ${ }^{29}$.

Observamos ainda como os meninos, ao mesmo tempo em que precisam, constantemente, provar que são machos e cavalheiros, precisam também provar que não são covardes. Assim, os meninos entendem que um menino deve ser cavalheiro com as meninas, mas também rebelde e bagunceiro: Igor diz: "nós somos cavalheiros: não falamos para a professora o que elas fazem em nós"; cavalheiro é "não bater em menina" (Diego). Eles complementam "se a menina tem um lápis pequeno, emprestar um grande que o menino tem" (Igor), "ser educado" (Diego); "mas menino, na realidade, também é bagunceiro" (Diego).

Já as meninas não querem ser santas, mas também não querem ser reconhecidas como barangas. Sobre não ser santa, elas justificam afirmando que batem nos meninos. Quando perguntada se os meninos batem muito nela, Érika respondeu (rindo): "não, porque a gente bate neles primeiro". Júlia reconheceu: "eles batem na gente, mas às vezes a gente dá uma batidinha neles". Nas situações de conflito, meninos e meninas são chamados por apelidos. $\mathrm{O}$ apelido que as meninas mais recebem é o de "baranga" (mulher feia), o que as leva a responder batendo nos meninos ou os chamando por outros apelidos: "os colegas me imitam e me chamam de baranga" (Amanda); "quando a gente brincava de meninas pegarem os meninos, às vezes nos chamavam de "barangas" (Mariana). Já o apelido que os meninos mais recebem é de gay. $\mathrm{O}$ exemplo abaixo (diário de campo) mostra este tipo de situação, vivida por uma das pesquisadoras:

Karine, uma menina que poderia ser definida (tanto pela professora, como pelos pesquisadores) como uma menina meiga, que sempre cuida da aparência e vive passando batom, estava sentada num banco, ao meu lado. Perto dela, Braian implicava, chamando-a de "baranga". Ela ficou calada, olhando para mim - acho que esperava que eu xingasse Braian, mas isso não aconteceu. Então perguntei: "que significa baranga"? Karine respondeu: "mulher feia". Indaguei:"e por que ele te chama assim"? Karine: "porque ele é gay".

A resposta de Karine parece não fazer muito sentido, pois qual seria a relação entre apelidar alguém de gay, após ter sido chamada de feia? A resposta encontra-se na generificação destas acusaçóes: chamar Braian de gay serviu como uma acusaçáo com um caráter tão pejorativo quanto o apelido que Karine recebeu (mulher feia). Esse aspecto reforça a dimensão pejorativa de "ser gay", ou seja, da homossexualidade, vinculada aos meninos.

Considerando as falas destacadas, é possível observar como alguns pressupostos de masculinidade e de feminilidade se constituem como noções homogêneas e universais, como dados desde sempre dessa maneira. Mas também pudemos salientar as diferentes configurações que se desenham, reconfiguram e ressignificam constantemente, sendo alvos de disputas no espaço do recreio. Enfatizando dois dos desdobramentos de gênero (seu caráter relacional e sua intersecção com outros marcadores sociais como a sexualidade, por exemplo), podemos argumentar que os mesmos discursos que produzem meninos como agressivos, cavalheiros ou covardes produzem as meninas como meigas, quietas ou barangas. Assim, múltiplas identidades, nem sempre harmônicas e convergentes são constituídas simultaneamente, nos mesmos processos educativos, alguns dos quais descrevemos aqui. 
Nesta pesquisa, problematizamos algumas concepções entendidas como naturais nas articulações de gênero com sexualidade, em um espaço especifico, para definir um modo de ser menino e de ser menina. Observar/mapear essas complexidades permitiu-nos desnaturalizar algumas das lógicas subjacentes à construção de masculinidades e feminilidades em vários espaços e processos, dentre eles um que parece inusitado à primeira vista, como o é o recreio escolar.

Observamos que o recreio é um espaço generificado e sexualizado. Nesse espaço as crianças não são tão livres quanto poderíamos acreditar. As crianças não brincam todas juntas, não fazem sempre o que querem, nem todas brincam em todos os espaços e, ainda, nem todas brincam do que gostariam. As brincadeiras são generificadas e sexualizadas e ocupam diferentes espaços no pátio. Ditos espaços são disputados, negociados ou impostos.
Observar ou mapear as construçôes sobre o gênero e a sexualidade entendidas como naturais para definir um jeito de ser menina e um jeito de ser menino permitem desnaturalizar as lógicas subjacentes sobre a construção de masculinidades e feminilidades no recreio, confrontando as representaçōes culturais que, dentre outras coisas, dão sustentação ao nosso próprio fazer pedagógico no espaço escolar. Gostaríamos, ainda, de destacar que a escola não se constitui um lugar homogêneo e harmônico e esta investigação nos permitiu que isso fosse visualizado. Ela é uma instituição onde se disputam, se aceitam, se rejeitam e se impóem significados através de processos em que as crianças se encontram inseridas participando de negociações culturais ou imposições tanto ou mais complexas e até tão cruéis quanto os processos de que participam os adultos.

\section{Notas}

a. Para maiores detalhes sobre Pós Estruturalismo e Estudos Culturais, ver Marisa Vorraber Costa ${ }^{30}$; Alfredo Veiga-Neto ${ }^{31}$, Tomas Tadeu da SILVA ${ }^{32}$. Para as articulaçōes entre Pós Estruturalismo e Feminismo, ver Guacira Lopes LourO ${ }^{27}$ e Dagmar E. Estermann MEYER ${ }^{23-24,33}$.

b. Esta forma de identificar as investigações etnográficas é referida por vários autores ${ }^{34-37}$ no contexto da antropologia, quando tratam de situações em que o pesquisador estuda a sua própria sociedade.

c. Por exemplo, nossa própria concepção de masculinidade e feminilidade.

d. Cabe destacar que nome da instituição e das crianças foram modificadas e que tanto a escola quanto os pais ou responsáveis assinaram o consentimento livre e esclarecido.

e. Para aprofundar a critica realizada ao conceito de papéis, ver Louro ${ }^{27}$.

f. Brincadeira que consiste numa disputa de habilidades de saltos sobre uma corda elástica estendida por três ou quatro metros de distância.

g. Os jogos de mãos são brincadeiras realizadas entre duas ou mais crianças, as quais se enfrentam batendo as mãos em diversas posições, combinado ritmos, cantos e posições das mãos e do corpo.

h. A autora adapta a expressão a partir de Bourdieu (várias obras).

i. Grifo nosso.

j. Tipo de pintura no cabelo, frequentemente usada pelas mulheres.

\section{Abstract}

\section{Gender and sexuality at school's recess}

In this study, from the slopes of Cultural Studies and Gender approaching the post-structuralism of Foucault, we aimed to understand how gender meanings that constitute different ways of being a boy or a girl in the playground area of a public school in Porto Alegre, Brazil are attributed. Through an ethnographic study, which lasted a year, and interviews with children, we focused on a second and a third basic education grades and identified an unofficial and unintended learning that occurs in the games of children, in which they learn ways to be boys and girls. In this context, we realized that there is an 
occupation of the schoolyard by gender, including occupancy and different ways of negotiation setting a geography of gender. We also observed a construction of sexuality in school, in which homosexuality is circumscribed to the detriment of the norm of heterosexuality.

KEY WORDS: Ethnography; Childhood; Gender; Sexuality.

\section{Referências}

1. Foucault M. Vigiar e punir. Petrópolis:Vozes; 2002.

2. Foucault M. Microfísica do poder. Rio de Janeiro: Graal; 2002.

3. Becker SH. Métodos de pesquisa em ciências sociais. São Paulo: HICITEC; 1997.

4. Knauth D, Ceres V, Agra Hassen M. Pesquisa qualitativa em saúde. Porto Alegre: TOMO; 2000.

5. Stigger MP. Esporte, lazer e estilos de vida: um estudo etnográfico. Campinas: Autores Associados; 2002.

6. Taylor SJ, Bogdan R. Introducción a los métodos cualitativos de investigación: la búsqueda de significados. Barcelona: Paidós; 1996.

7. Albarello L, Digneffe F, Hiernaux J-P, Maroy C, Ruquoy D, Saint-Georges P. Práticas e métodos de investigação em ciências sociais. Lisboa: Gradiva; 1997.

8. Burguess RG. A pesquisa de terreno: uma introdução. Lisboa: Celta; 1997.

9. Delfos MF. Me escuchas? Como conversar con niños de cuatro a doce años. Amsterdam: Bernard Van Leer Foundation; 2001.

10. Fabri Dermatini Z. Infância, pesquisa e relatos Orais. In: Goulat AL, Fabri Dermatini ZB, Prado DP, organizadores. Por uma cultura da infância: metodologias de pesquisa com crianças. Campinas: Autores Associados; 2002.

11. Cruz T. Meninas e meninos no recreio: gênero, sociabilidade e conflito [tese]. São Paulo (SP): Universidade de São Paulo, Faculdade de Educação; 2004.

12. Fabes RD, Lynn Martin C. Social cognition on the playground: children's beliefs about playing with girls versus boys and their relations to sex segregated play. J Soc Pers Relat. 1999;16:751-71.

13. Pellegrini AD, Kato K, Blatchford P, Baines, E. A short-term longitudinal study of children's playground games across the first year of school: implications for social competence and adjustment to school. Am Educ Res J. 2002;39:991-1015.

14. Grugeon E. Implicaciones de género en la cultura del patio del recreo. In: Woods P, Hammersley M, organizers. Género, cultura y etnia en la escuela: informes etnográficos. Madrid: Ministerio de Educación y Ciencia; 1995.

15. Geertz C. A interpretação das culturas. Guanabara: Koogan; 1989.

16. Thorne B. Gender play: girls and boys in school. New Jersey: Rutgers University Press; 1997.

17. Altmann H. Rompendo fronteiras de gênero: Marias (e) homens na educação física [dissertação]. Belo Horizonte (MG): Universidade Federal de Minas Gerais, Faculdade de Educação; 1998.

18. Neto C. Jogo \& desenvolvimento da criança. Lisboa: Ediçōes FMH; 1997.

19. Epstein D, Kehily M, Mac an Gaill M, Redman P. Boys and girls come out: making masculinities and femininities in school playgrounds. Men and Masculinities. 2001;4:158-72.

20. Boylle E, Marshall LN, Robeson W. Gender at play: fourth-grade girls and boys on the playground. Am Behav Sci. 2003;24:1326.

21. Louro GL. Corpo, escola e identidade. Educ Real. 2000;25:59-76.

22. Nicholson L. Interpretando o gênero. Estud Fem. 2000;8:9-42.

23. Meyer D. A arquitetura de um regime de representação cultural: a escola elementar teuto-brasileiro-evangélica no Rio Grande do Sul (1909-1939). REDES: Rev Des Regional. 2001;6(n.Esp.):53-73.

24. Meyer D. Gênero e educação: teoria e política. In: Louro G, Neckel JF, Goellner S, organizadores. Corpo, gênero e sexualidade: um debate contemporâneo na Educação. Petrópolis: Vozes; 2003.

25. Marivoet S. Aspectos sociológicos do desporto. Lisboa: Livros Horizonte; 1998.

26. Steinberg S, Kinchelo EJ, organizers. Cultura infantil: a construção corporativa da infância. Rio de Janeiro: Civilização Brasileira; 2000.

27. Louro GL. Gênero, sexualidade e educação: uma perspectiva pós-estruturalista. 4a ed. Petrópolis: Vozes; 2001.

28. Swain J. The role of sport in the construction of masculinities in english independent junior school. Sport Educ Soc. 2006;11:317-35. 
Wenetz I, et al.

29. Meyer DE. Corpo, violência e educação: uma abordagem de gênero. In: Junqueira RD, organizador. Educação e diversidade sexual: problematizaçôes sobre a homofobia na escola. Brasília: Ministério da Educação/SEDAC; 2009.

30. Costa Vorraber M. Estudos culturais: para além das fronteiras disciplinares. In: Costa MV, organizadora. Estudos culturais em educação. Porto Alegre: Editora da Universidade Federal de Rio Grande do Sul; 2000.

31. Veiga-Neto A. Michel Foucault e os estudos culturais. In: Costa, MV, organizadora. Estudos culturais em educação. Porto Alegre: Editora da Universidade Federal de Rio Grande do Sul; 2000. p. 37-69.

32. Silva TT. Documentos de identidade: uma introdução às teorias do currículo. 2a ed. Belo Horizonte: Autêntica; 2000.

33. Meyer D. Cultura e docência teuto-brasileiro-evangélica no Rio Grande do Sul. Santa Cruz do Sul: EDUNISC; 2000.

34. Magnani JGC. Festa no pedaço: cultura popular e lazer na cidade. São Paulo: Brasiliense; 1984.

35. Da Matta R. Relativizando: uma introdução à antropologia social. Petrópolis: Vozes; 1987.

36. Durham E. A pesquisa antropológica com populações urbanas: problemas e perspectivas. In: Cardoso R, organizadora. A aventura antropológica. 2a ed. São Paulo: Paz e Terra; 1998. p.17-37.

37. Laplantine F. Aprender antropologia. 8a ed. São Paulo: Brasiliense; 1994.

\begin{tabular}{r|r} 
ENDEREÇo & \\
Ileana Wenetz & \\
Universidade Federal de Santa Catarina & Recebido para publicação: 28/03/2012 \\
R. Antonio Francisco da Silveira, 529 apto. 1 & Aceito: 01/10/2012 \\
88040-160 - Pantanal - SC - BRASIL & \\
e-mail: ilewenetz@gmail.com & \\
& \\
\hline
\end{tabular}

128 • Rev Bras Educ Fís Esporte, (São Paulo) 2013 Jan-Mar;27(1):117-28 